\title{
As conveniências da Educação Ambiental no ambiente escolar
}

\section{The conveniences of Environmental Education in the school environment}

\section{Las comodidades de la Educación Ambiental en el entorno escolar}

Paulo Eduardo de Oliveira Sousa ORCID: https://orcid.org/0000-0002-0297-6109 Universidade Federal de Lavras, Brasil E-mail: pauloplanalto@yahoo.com.br

Kátia Soares Moreira

ORCID: https://orcid.org/0000-0001-8724-3133 Universidade Federal de Lavras, Brasil

E-mail: katiasoaresmoreira@hotmail.com

Heitor Soares Moreira

ORCID: https://orcid.org/0000-0002-4546-8390 Universidade Federal de Lavras, Brasil E-mail: hsmengenheir@yahoo.com.br

José Ricardo de Oliveira Sousa

ORCID: https://orcid.org/0000-0002-6470-1952 Faculdade de Filosofia e Teologia, Brasil E-mail: oliveirasousa36@gmail.com

Juliano Jorge de Freitas Salgado

ORCID: https://orcid.org/0000-0001-8660-2560 Universidade Federal de Lavras, Brasil

E-mail: juliano.salgado@estudante.ufla.br

\begin{abstract}
Resumo
A Educação Ambiental (EA) é uma realidade implementada dentro das escolas através de uma política pública com proposta de formar e preparar cidadãos para a reflexão crítica, porém o modelo atual, conservacionista e pragmático, implementados levam em consideração os aspectos históricos e o modelo econômico sem considerar o entorno social, político e cultura. Observa-se várias definições de Educação Ambiental correspondendo aos interesses e não necessariamente levam em consideração a relação homem e meio ambiente.
\end{abstract}

Palavras-chave: Meio ambiente; Educação; Interdisciplinaridade.

\begin{abstract}
Environmental Education (EA) is a reality implemented within schools through a public policy aimed at training and preparing citizens for critical reflection, but the current conservationist and pragmatic model implemented take into account the historical aspects and the economic model. without considering the social, political and cultural surroundings. There are several definitions of Environmental Education corresponding to the interests and do not necessarily take into consideration the relationship between man and environment.

Keywords: Environment; Education; Interdisciplinarity.

\section{Resumen}

La Educación Ambiental (EA) es una realidad implementada dentro de las escuelas a través de una política pública con el propósito de capacitar y preparar a la ciudadanía para la reflexión crítica, pero el modelo actual, conservacionista y pragmático, implementado toma en cuenta los aspectos históricos y el modelo económico sin considerar la entorno social, político y cultural. Existen varias definiciones de Educación Ambiental que corresponden a intereses y no necesariamente toman en cuenta la relación entre el hombre y el medio ambiente.

Palabras clave: Medio ambiente; Educación; Interdisciplinariedad.
\end{abstract}

\section{Introdução}

A questão do meio ambiente está fortemente ligada a educação. A história da educação se faz da constante construção do processo ensino-aprendizagem, permeado por mudanças e transformações ocorridas no tempo, que favorecem as reflexões em torno da Educação Ambiental (EA). Importante frisar que ao se tratar sobre o meio ambiente, constata-se a multiplicidade do conceito em diversas ciências, por isso, torna necessária e possível que a educação se encaminhe para a conscientização dos 
indivíduos, grupos sociais e da sociedade em prol de novas condutas de vida no planeta, que aproxime o homem da natureza. (Layrarques \& Lima, 2011, P. 10)

Os educadores têm um papel estratégico na inserção da EA no cotidiano escolar, qualificando os alunos para um posicionamento crítico, que tenha como horizonte a transformação de hábitos e práticas sociais além da formação de uma cidadania ambiental. Nesse sentido, a Educação Crítica é um instrumento valioso no campo de disputa atravessado pela Educação Ambiental conservadora embalada pela racionalidade dominante. (Rodrigues \& Guimarães, 2011, p. 51)

Dessa forma, esse trabalho pretende apresentar um panorama das diferentes possibilidades da interferência da EA no cotidiano escolar, apresentando algumas concepções.

\section{Metodologia}

Este trabalho trata-se de uma pesquisa descritiva, qualitativa, do tipo bibliográfica, baseada em revisão narrativa. Na pesquisa qualitativa, em geral, o pesquisador é o principal instrumento e os dados coletados são preferencialmente descritivos (Pereira et al., 2018). Para o desenvolvimento desta pesquisa foi necessário o levantamento do referencial bibliográfico, como livros, artigos e sites que abordam temas relacionados ao meio ambiente e a Educação Ambiental.

\section{Repensar Sobre as Perspectivas da Educação Ambiental}

Para superar essa dicotomia homem natureza, está a implementação da EA efetiva e permanente nas escolas. Para que esta efetivação seja concretizada é importante o esclarecimento dos professores quanto ao conceito de EA e como ela pode ser trabalhada transversalmente para que de fato aborde a importância do meio ambiente frisando a o cuidado com a natureza por meio de ações tanto no ambiente escolar como na própria comunidade em uma abordagem sistêmica que envolva escola, família, comunidade, sociedade.

Teixeira e Torales (2014) propõem uma reflexão do campo educativo-ambiental no país onde sua raiz, seu objeto seria fundamentalmente a nossa relação com o meio ambiente, que deveria articular-se em diferentes dimensões educacionais como a intelectual, a moral, a social e a política.

Segundo Rodrigues e Guimarães (2011) a EA é um campo de disputas e que se faz necessário um posicionamento e a clareza de que não existe neutralidade na prática pedagógica e que a EA pode ser mecanismo de dominação ideológico. Diante da dificuldade de conceituação da EA em um contexto formal de educação também se encontra o desafio de um pensamento crítico e reflexivo que explicite as consequências ambientais de nossas práticas sociais.

Com foco na formação integral do educando e com vistas no desenvolvimento de uma ética de responsabilidade, encontramos no pensamento de Paulo Freire as balizas para a construção de uma dinâmica de ensino-aprendizagem em Educação Ambiental significativa e libertadora.

Freire traz aos educadores socioambientais que é possível suplantar praticas conservadoras, estimulando o educando a relacionar-se e interagir de forma ética, crítica e curiosamente com o mundo, com os outros habitantes do Planeta de forma sustentável, como sujeito histórico e protagonista de um mundo mais humano - dimensões constitutivas da práxis sócio pedagógica libertadora. (Dickmann; Carneiro, 2012, p.98).

As políticas públicas nacionais em alguns momentos resultaram-se a sua dimensão reprodutora das condições socioambientais que caracterizariam a crise ambiental mundial e em outros discursos da EA crítica e emancipatória.

Nessa perspectiva, propõe-se uma reflexão sobre como a EA em uma perspectiva de práticas educativas no ambiente formal em relação a sua conceituação e quais as dificuldades de pensar uma EA de forma interdisciplinar tendo uma visão mais crítica e seu papel como política pública. 


\section{Visões Diferentes da Educação Ambiental e suas Implementações}

Constata-se ao tratar sobre o meio ambiente a multiplicação do conceito em diversas ciências, por isso, torna necessária pensar um conceito universal sobre EA que se encaminhe para a conscientização dos indivíduos, grupos sociais e da sociedade em prol de novas condutas de vida no planeta, que aproximem o homem e a natureza. E entre os desafios para o equilíbrio vital entre a humanidade e o planeta. A implementação da EA efetiva e permanente possibilita a conscientização por meio de ações que abordem a importância do cuidado com a natureza por meio de ações tanto no ambiente escolar como na própria comunidade em uma abordagem sistêmica, que envolva família, comunidade, sociedade. (Jacobi, 2003, p. 192)

O meio ambiente, vem sofrendo as consequências devido as ambições desenfreadas do homem por um desenvolvimento que visa somente o lucro. Mesmo com tantos indícios que o modelo assumido pelo desenvolvimento capitalista leva a extinção do próprio homem na terra, não é suficiente para transformar a relação com o meio ambiente. Por isso a relevância de uma EA que de fato leve o homem a tomar consciência do seu papel transformador da sociedade, saindo do papel meramente passivo. (Trein, 2012, p.305)

Para Layrargues (2011), a EA conservacionista foi uma das primeiras formas de conceitos adotadas no ambiente escolar, tinha como premissas práticas individuais, idealizando ações pontuais, porém ecologicamente corretas. Para Kawasaki e Carvalho (2009) esse modelo tem como meta minimizar ou resolver os problemas ambientais locais. Essa vertente tem o lema conhecer para amar, amar para preservar. Uma das características da visão conservacionista é focar na crise e nos problemas ambientais, desvinculando as condições sociais, políticas e culturais.

Um outro modelo bastante difundido foi a EA pragmática que busca soluções práticas para os problemas ambientais. Acredita na implantação de normas a serem seguidas para conter as consequências do sistema capitalista de produção. Implementa mecanismos de compensação para corrigir a imperfeição de um sistema produtivo baseado em consumos elevados, na obsolescência planejada e nos descartáveis (Layrargues \& Lima, 2011, p. 10).

Responsabiliza o indivíduo pela degradação e espera desse ator sacrifícios a fim de contornar o consumo excessivo. Trein (2012) alerta que os princípios do capitalismo precisam ser denunciados para a mobilização e reorganização da sociedade conforme modelos alternativos (Grün, 1996, p. 60; Trein, 2012, p. 307).

A partir desses conceitos apresentados, percebe-se que a EA está atrelada a uma visão da EA pouco prática, conservacionista e pragmática, ou seja, ações voltadas para o cuidado com a natureza e com a reciclagem. Pouco se trabalha a questão de forma crítica e reflexiva e ainda de maneira mais ampla e complexa. Conforme Trein (2012) "vivemos em condição de exploração e alienação tanto da natureza quanto dos seres humanos como forma necessária de reprodução do capital" (Trein, 2012, p. 309).

\section{Conclusão}

Os modelos conservacionista e pragmático são reflexos do modelo econômico que limita e interfere na implantação de nova proposta de uma EA mais crítica e questionadora. Ainda se faz necessário pesquisar mais sobre um modelo de educação crítica que traz a realidade do consumo excessivo e seus impactos a fim de avaliar a mudança de comportamento e atitude dos alunos e professores, consumidores em geral. Para isso, faz-se necessário repensar as práticas pedagógicas nas escolas que muitas reforçam os modelos conservacionista e pragmático e não para uma reflexão crítica acercar do Educação Ambiental que de fato proporcionem uma transformação na interação homem e natureza.

\section{Referências}

Dickmann, I., \& Carneiro, S. M. M. (2012). Paulo Freire e Educação ambiental: contribuições a partir da obra Pedagogia da Autonomia. Revista Educação Pública, 21(45), 87-102. 10.29286/rep.v2li45.334 
Research, Society and Development, v. 10, n. 3, e47510313081, 2021

(CC BY 4.0) | ISSN 2525-3409 | DOI: http://dx.doi.org/10.33448/rsd-v10i3.13081

Festozo, M. B., Queixas, R. C., Junior, A. N., \& Tozoni-Reis, M. C. (2018). Relações Históricas entre a Educação Ambiental e a Participação Social. 11, 253266. 10.20952/REVTEE.V11124.6677

Freire, P. (2011). Pedagogia do oprimido. (50a ed.), Paz e Terra.

GRÜN, M. (1996). Ética e Educação Ambiental: a conexão necessária. Papirus.

Kawasaki, C. S., \& Carvalho, L. M. (2009). Tendências da Pesquisa em Educação Ambiental. Educação em revista. 25(3), 143-157.

Layrargues, P. P., \& Lima, G. F. C. (2011). Mapeando as Macro-tendências Políticos - Pedagógicas da Educação Ambiental Contemporânea no Brasil. https://www.icmbio.gov.br/educacaoambiental/images/stories/biblioteca/educacao_ambiental/Layrargues_e_Lima___Mapeando_as_macrotendências_da_EA.pdf

Pereira A. S. et al. (2018). Metodologia da pesquisa cientifica. UFSM. https://repositorio.ufsm.br/bitstream/handle/1/15824/Lic_Computacao_MetodologiaPesquisa-Cientifica.pdf?sequence $=1$.

Rodrigues, J. N., \& Guimarães, M. (2011). Algumas contribuições marxistas à Educação Ambiental (EA) crítico-transformadora. Revista Educação Pública, 20(44), 501-518. 10.29286/rep.v20i44.320

Trein, E. S. (2012). A Educação Ambiental Crítica: crítica de que? Revista Contemporânea de Educação, 7(14), 295-308. 10.20500/rce.v7i14

Teixeira, C., \& Torales, M. A. (2014). A questão ambiental e a formação de professores para a educação básica: um olhar sobre as licenciaturas. Educar em Revista, spe3, 127-144. 10.1590/0104-4060.38111 